\title{
Educação literária e representações da leitura: itinerários da formação de
}

\author{
professores
}

\section{Literary education and conceptions of reading: paths of teacher training}

\author{
Dulce Melão \\ Instituto Politécnico de Viseu
}

\begin{abstract}
Resumo
Este estudo tem como objetivo investigar as representações da leitura e da educação literária de futuros professores e o seu contributo para o repensar da sua formação. Participaram 4 estudantes inscritos na unidade curricular de Prática de Ensino Supervisionada em Educação de Infância e $1 .^{\circ}$ Ciclo do Ensino Básico III (2015-2016). Foram analisadas: i) 52 planificações individuais, incidindo nos domínios da Leitura e Escrita e da Educação Literária; ii) 8 registos de observações em contexto de supervisão. As representações da leitura e da educação literária dos estudantes revelaram a necessidade de rever os seus itinerários de formação.
\end{abstract}

Palavras-chave: formação de professores, educação literária, leitura, representações, supervisão.

\begin{abstract}
This study aims to investigate the conceptions of reading and literary education of future teachers and their contribution to rethinking their training. Participants were 4 students enrolled in the curricular unit of Supervised Teaching Practice in Early Childhood Education and Primary Education III (2015-2016). The following were analysed: i) 52 individual lesson plans, focusing on the domains of Reading and Writing and of Literary Education; ii) 8 records of observations in the context of supervision. The conceptions of reading and literary education of the students revealed the need to review their training itineraries.
\end{abstract}

Keywords: teacher training, literary education, reading, conceptions, supervision.

\section{Enquadramento do estudo}

A leitura tem recebido atenção renovada em contexto escolar, merecendo destaque nos documentos curriculares em vigor (por exemplo, Buescu, Morais, Rocha \& Magalhães, 2015), bem como em iniciativas e em atividades que se têm revestido de um cariz diversificado. Na Resolução do Conselho de Ministros n. ${ }^{\circ}$ 48D/2017 (31 de março) é frisado que: «(...) o domínio alargado da competência da leitura é perspetivado como condição fundamental para a construção e consolidação de uma sociedade livre, com coesão social, acesso democrático à informação, ao conhecimento, e à criação e fruição culturais» (Presidência do Conselho de Ministros, 2017, p. 1692(5)), sendo reconhecido que é necessário investir numa política pública de leitura. Nesse sentido, nas linhas orientadoras do Plano Nacional de Leitura 2017-2027 (PNL) é sublinhada, entre outros aspetos relevantes que dizem respeito à sociedade em geral, a importância de «promover projetos de formação de professores, mediadores de leitura, agentes culturais e outros intervenientes» (Presidência do Conselho de Ministros, 2017, p. 1692-(6)).

$\mathrm{Na}$ literatura de especialidade, para além da ênfase colocada na importância da leitura na universidade (Olivares \& Arbona, 2016; Sánchez, 2016) é igualmente reforçada a necessidade da formação de professores cuja missão é formar leitores ter em atenção as práticas de leitura dos primeiros (Arruda \& Guimarães, 2016; Souza \& Carrera, 2017), podendo tais práticas fornecer dados relevantes que contribuam para uma reflexão apurada do desenho da sua formação no âmbito do $1 .^{\circ}$ e do $2 .^{\circ}$ Ciclo de Bolonha.

$\mathrm{O}$ destaque conferido à Educação Literária no Programa e Metas Curriculares de Português do Ensino Básico (Buescu et al., 2015), em articulação com o domínio da Leitura e Escrita, é igualmente um aspeto de relevo a ter em consideração no que à formação dos futuros professores e educadores diz respeito, dado ter implícito o conhecimento de obras/de textos que lhes possibilitem ir ao encontro dos objetivos e respetivos descritores de desempenho traçados no referido domínio.

Face ao exposto, compreender as representações da leitura e da educação literária dos estudantes que frequentam um 2. ${ }^{\circ}$ ciclo de estudos de Bolonha (Mestrado em Educação Pré-Escolar e Ensino do 1. ${ }^{\circ}$ Ciclo do Ensino Básico) afigura-se relevante, dado o seu futuro papel no que respeita à formação de leitores. Entende-se que os objetivos e respetivas atividades de ensino-aprendizagem delineados pelos estudantes no âmbito da Prática de Ensino Supervisionada (PES) são porto de abrigo privilegiado de tais representações, podendo facultar elementos relevantes sobre as mesmas.

$\mathrm{Na}$ seção seguinte, descrevemos e explicitamos os objetivos que nortearam o nosso estudo, bem como as opções metodológicas consideradas mais adequadas neste contexto.

\section{Objetivos do estudo e método}

Os conteúdos programáticos no âmbito da unidade curricular de Prática de Ensino Supervisionada em 
Educação de Infância e $1 .^{\circ}$ Ciclo do Ensino Básico III (incluída no plano de estudos do $2 .^{\circ}$ ano do Mestrado em Educação Pré-Escolar e Ensino do $1 .^{\circ}$ Ciclo do Ensino Básico) contemplavam quatro dimensões (explicitadas no seu programa): i) dimensão profissional, social e ética; ii) dimensão de desenvolvimento profissional ao longo da vida; iii) dimensão de desenvolvimento do ensino e da aprendizagem e iv) dimensão de participação na escola e relação com a comunidade. No âmbito da nossa reflexão, na medida em que pretendíamos compreender as representações da leitura e da educação literária dos estudantes, interessou-nos, sobretudo, atentar na dimensão do ensino e da aprendizagem, nomeadamente no que respeita aos planos de aula concebidos (relativos ao domínio da preparação e organização das atividades letivas), em contexto do $1 .^{\circ}$ Ciclo do Ensino Básico.

A abordagem privilegiada neste estudo foi de natureza qualitativa, tendo como referencial metodológico o estudo de caso. Entendeu-se que tal se adequaria à complexidade do objeto de estudo em causa - as representações dos estudantes - possibilitando o aprofundamento da sua compreensão e favorecendo uma dimensão interpretativa mais rica (Coutinho, 2011; 2015; Sánchez, 2015).

\section{Participantes}

Os participantes no nosso estudo foram 4 estudantes (E) inscritos na unidade curricular de Prática de Ensino Supervisionada III (PES), no $1 .^{\circ}$ semestre do ano letivo 2015/2016 (Mestrado em Educação Pré-Escolar e Ensino do 1. ${ }^{\circ}$ Ciclo do Ensino Básico, 2. ${ }^{\circ}$ ano), na Escola Superior de Educação de Viseu. No semestre referido, a PES III foi desenvolvida em contexto do $1 .^{\circ}$ Ciclo do Ensino Básico, em várias escolas do concelho de Viseu, sendo realizada por dois dos formandos no $2 .^{\circ}$ ano de escolaridade e pelos outros dois no $3 .^{\circ}$ ano de escolaridade. A escolha dos anos de escolaridade indicados deveu-se às nossas responsabilidades de supervisão, no ano letivo mencionado.

\section{Instrumentos}

Utilizamos como instrumentos as planificações entregues semanalmente pelos estudantes (E), perfazendo um total de 52 (13 de cada; doravante identificadas no texto como «P», seguindo-se o respetivo número). Adicionalmente consideramos também os registos das observações (8, no total; indicadas no texto como «RO», seguindo-se o respetivo número) realizadas em contexto de supervisão destes estudantes, pelo modo como ecoam o desenvolvimento do processo formativo e das práticas educativas que lhe estão inerentes.

\section{Procedimentos}

Relativamente às planificações, foram tidas em consideração, no que respeita à nossa análise: (i) as atividades de ensino-aprendizagem no âmbito da área curricular de Português (respeitantes aos domínios da Educação Literária e da Leitura e Escrita) e, sempre que se considerou pertinente, a sua possível articulação com outras áreas curriculares; ii) os objetivos elencados para as atividades; (iii) os recursos utilizados.
Face aos objetivos enunciados, foi privilegiada a técnica da análise de conteúdo das planificações, complementada pela dos registos das observações. Seguiram-se os passos sugeridos por Bardin (2004), tendo sido estabelecidas: i) categorias a posteriori, no entendimento de que tal poderia dar voz às representações da leitura e da educação literária de forma mais ampla e pormenorizada; ii) categorias a priori, quando se considerou que se adequariam, em particular, aos propósitos do estudo, face aos instrumentos utilizados que foram privilegiados (as planificações) e aos domínios em análise: Leitura e Escrita e Educação Literária.

\section{Resultados}

No âmbito das atividades letivas, no que se refere ao desenvolvimento do ensino e da aprendizagem, a nossa atenção centrou-se nos domínios da Leitura e Escrita e da Educação Literária, sendo considerados: i) a relação entre os conteúdos e os objetivos elencados; ii) as tipologias textuais preferidas; iii) a articulação dos aspetos anteriormente mencionados com a operacionalização dos descritores de desempenho do Programa e Metas Curriculares de Português do Ensino Básico (Buescu et al., 2015). Nas menções a este documento curricular, no que se refere às metas, por questões de uniformização, são indicados, entre parêntesis, em primeiro lugar, o domínio referido, seguindo-se, respetivamente, o ano de escolaridade, o número do objetivo e do seu descritor de desempenho e a página da citação (ex. IEL2.19.4, p. 51).

Reportar-nos-emos, em primeiro lugar, aos planos de aula relativos ao $2 .^{\circ}$ ano de escolaridade e, seguidamente, aos respeitantes ao $3 .^{\circ}$ ano de escolaridade.

Relativamente à relação entre os conteúdos e os objetivos elencados, no que se refere ao $2 .^{\circ}$ ano de escolaridade, foi possível compreender que se articulavam de forma harmoniosa no domínio da Leitura e Escrita, nomeadamente no que se refere à compreensão de texto, sendo destacadas as categorias «Alargamento do vocabulário» (18 ocorrências), «Organização da informação do texto» (12 ocorrências) e «Monitorização da compreensão» (10 ocorrências).

As categorias «Fomento da imaginação» (3 ocorrências) e «Escrever textos» (6 ocorrências) foram mais depreciadas, possivelmente por colocarem desafios acrescidos aos estudantes, o que se teria repercutido na prossecução das atividades propostas. Os registos das observações (RO2; RO3; RO4) possibilitaram corroborar tais ilações.

Importa ainda salientar a relação estreita estabelecida entre estas categorias e as atividades desenvolvidas pelos estudantes, tendo como matéria-prima privilegiada a narrativa, muito destacada nas planificações em análise, como frisaremos mais adiante.

No que se refere à abordagem da poesia, foram apenas apresentadas, nos planos de aula elaborados pelos estudantes (P5, P6, P17 e P18), de forma ilustrativa, as suas características formais (por exemplo, «rima», «verso», «estrofe»), com recurso, em exclusivo, ao PowerPoint, sem apoio de exemplos que possibilitassem a sua fruição, no intuito de cumprir o objetivo que os 
estudantes definiram como «identificação das características do texto poético».

A análise realizada permitiu-nos inferir que foram excluídos os conteúdos programáticos respeitantes à «Memorização e recitação» (Buescu et al., 2015, p. 12) que permitiriam a operacionalização de descritores de desempenho como «Ler em coro pequenos poemas» (IEL2.19.4., p. 51) ou «Dizer pequenos poemas memorizados» (IEL2.23.2, p. 52), incrementando, possivelmente, o prazer de ler. Importa também sublinhar que, em aulas subsequentes, não foi dada continuidade ao trabalho realizado, o que poderá ter dificultado a compreensão das características do texto poético por parte dos/das alunos/alunas.

No âmbito da Iniciação à Educação Literária sobressaíram as categorias «Promoção da aquisição de conhecimentos sobre o texto» (16 ocorrências) e «Promoção da leitura silenciosa» (11 ocorrências). Menor relevo foi dado ao "Incentivo do gosto pela leitura» (3 ocorrências), ao «Incremento do hábito da leitura» (2 ocorrências), ao «Estabelecimento de inferências» (2 ocorrências) e à "Antecipação de conteúdos» ( 2 ocorrências).

Depreendemos que a antecipação de conteúdos, bem como o estabelecimento de inferências (de sentimento atitude), poderiam ter sido operacionalizados no âmbito das atividades de ensino-aprendizagem propostas nos planos de aula, face às tipologias textuais indicadas (por exemplo, no caso dos textos narrativos, maioritariamente preferidos). No entanto, os estudantes focaram preferencialmente a sua atenção na «aquisição de conhecimentos» sobre a tipologia textual a explorar, depreciando o prazer na leitura, cuja relevância está implícita desde as primeiras páginas do Programa $e$ Metas Curriculares de Português do Ensino Básico, nomeadamente no que respeita ao objetivo global «Apreciar criticamente a dimensão estética dos textos literários, portugueses e estrangeiros, e o modo como manifestam experiências e valores» (Buescu et al., 2015, p. 5).

As tipologias textuais favorecidas pelos estudantes merecem atenção redobrada, por contribuírem para desvelar as suas representações da leitura e da educação literária. Assim, da análise dos seus planos de aula emergiu a preferência por textos narrativos $(18$, no total; 8, relativamente a E1 e 10, no caso de E2), sobretudo de autores Portugueses (António Torrado, Maria Isabel Mendonça Soares, Alice Vieira e António Mota). Não foram selecionados textos mencionados na «Lista de obras e textos para a Iniciação à Educação Literária», embora tenha existido a preocupação de eleger «textos da tradição popular» (IEL2.19.1., p. 51), tais como o «Caldo de pedra» e a «Lenda de S. Martinho». No que refere ao texto poético, os estudantes selecionaram, respetivamente, a obra $A$ menina que não gostava de fruta de Cidália Fernandes (E1) e o texto «O mais importante» (E2) da obra Alfabetizar com amor, de Isabel Soares.

O cruzamento dos conteúdos programáticos com os objetivos e os descritores de desempenho operacionalizados nas metas curriculares permitiu-nos inferir que no âmbito do objetivo «Compreender o essencial dos textos escutados e lidos» (IEL2.20, p. 51) foi privilegiado apenas duas vezes o descritor de desempenho «Antecipar conteúdos com base no título e nas ilustrações (IEL2.20.1., p. 51). Importa notar que a operacionalização deste descritor de desempenho foi realizada unicamente com recurso ao PowerPoint, aspeto sobre o qual refletimos na subseção seguinte. A preferência dos estudantes recaiu, antes, com muita frequência, na prossecução do objetivo «Organizar a informação de um texto lido» (LE2.10, p. 49), nomeadamente na operacionalização do descritor de desempenho «Relacionar diferentes informações contidas no texto, de maneira a pôr em evidência a sequência temporal de acontecimentos, mudanças de lugar, encadeamentos de causa e efeito» (LE2.10.2., p. 50). Tal preferência relaciona-se estreitamente com a utilização recorrente dos textos narrativos, possivelmente por serem considerados menos complexos que os textos poéticos ou por gosto pessoal. Outros estudos já realizados corroboram a depreciação dos textos poéticos por parte de estudantes futuros profissionais da Educação (Granado, 2014; Melão, 2016a), apontando para a necessidade de dar maior atenção à sua formação, de modo a que o gosto pela poesia possa germinar.

No que diz respeito ao $3 .^{\circ}$ ano, quanto à relação entre os conteúdos e os objetivos referidos verificamos que se destacaram as seguintes categorias: i) «Identificação do tema ou do assunto do texto» (15 ocorrências); ii) Monitorização da compreensão (11 ocorrências); iii) «Aquisição e organização de conhecimentos sobre o texto» (10 ocorrências). $\mathrm{O}$ «Fomento da leitura em voz alta» (3 ocorrências) e a «Planificação da escrita de textos» (3 ocorrências) foram pouco valorizados.

Relativamente à Educação Literária, foi possível compreender que a atenção que lhe é concedida nos 26 planos de aula em análise neste nível de escolaridade não é suficiente, face às múltiplas omissões de aspetos que consideramos fundamentais no que se refere à formação de leitores. As categorias que menos se destacaram possibilitam depreender que foi depreciada a «Realização de inferências» ( 2 ocorrências), bem como o «Confronto das previsões feitas sobre o texto com o assunto do mesmo» (3 ocorrências), aspetos relevantes no âmbito do objetivo «Compreender o essencial dos textos escutados e lidos» (IEL3.22, p. 56). Quanto ao objetivo «Dizer e escrever, em termos pessoais e criativos», primam pela ausência «Memorizar e dizer poemas, com clareza e entoação adequadas» (IEL3.25.1) e «Escrever pequenos poemas, recorrendo a poemas modelo» (IEL3.25.4). Tal ausência poderá ter subjacente: i) o número escasso de textos poéticos selecionados pelos estudantes; ii) a sua dificuldade em planificar atividades que possibilitassem a operacionalização de tais descritores de desempenho.

As categorias «Resposta a questões sobre os textos» (16 ocorrências), «Identificação das personagens principais» (12 ocorrências) e «Leitura e exploração em grande grupo do texto» ( 9 ocorrências) foram as que mais se destacaram, estando estreitamente relacionadas, à semelhança do sucedido com as planificações do $2 .^{\circ}$ ano de escolaridade, com a preferência dos estudantes pelo texto narrativo (E3, 9 ocorrências; E4, 8 ocorrências), comparativamente ao texto poético ( 2 ocorrências cada - 
E3 e E4) e ao texto dramático (2 ocorrências cada - E3 e E4). Relativamente ao texto narrativo, as preferências dos estudantes recaíram em obras referidas no Plano Nacional de Leitura - por exemplo, Dez dedos, dez segredos de Maria Alberta Menéres (P31) - e, sobretudo, em obras / em textos da lista de obras / textos indicada nas Metas Curriculares de Português - por exemplo, $O$ senhor do seu nariz e outras histórias, de Álvaro Magalhães (P33 e P44), Robertices de Luísa Dacosta (P37), «Boa sentença» e «O fato novo do sultão» de Guerra Junqueiro (P25 e P45). Relativamente ao texto poético, foram selecionados dois poemas do livro Ciência para meninos em poemas pequeninos de Regina Gouveia (P29; P40). Quanto aos textos dramáticos escolhidos, verificou-se que eram de autor anónimo (P32; P50), provenientes de materiais disponíveis online, aspeto que nos parece merecer particular atenção, face à especificidade da formação destes estudantes e às suas futuras responsabilidades em contexto educativo.

No que respeita aos recursos indicados nos planos de aula do $2 .^{\circ}$ ano de escolaridade, foi possível inferir que os estudantes utilizavam suportes impressos e digitais, privilegiando fortemente estes últimos.

Relativamente aos suportes impressos, verificou-se, globalmente: i) o recurso reiterado ao manual escolar para a promoção de atividades de leitura, sendo favorecidos excertos de textos narrativos; ii) a preferência por fichas de trabalho, elaboradas pelos estudantes. Apenas dois planos de aula fazem menção à utilização do livro e ao seu relevo no âmbito das atividades planificadas. Esta omissão merece-nos particular reparo por várias razões: i) pelo facto de os documentos curriculares em vigor apontarem para a importância do contacto com o livro e para o papel a desempenhar pelo(a) professor(a) no que respeita à sua exploração e inclusão, devidamente fundamentada, no âmbito da prossecução dos objetivos do domínio da Educação Literária; ii) pelo reconhecimento que o livro exige a participação ativa do leitor, abrindo modos de fruição diversificados e inesperados (Fajardo, 2014; Saldanha \& Amarilha, 2016); iii) por silenciar o livro ter como consequência eliminar a etapa da pré-leitura, relegando para segundo plano a crescente riqueza que os elementos paratextuais proporcionam, podendo contribuir para a motivação para a leitura (Melão, 2016b; Sebastián, 2016).

Os estudantes recorreram, sobretudo, à apresentação dos textos a explorar com recurso ao PowerPoint, presente na maioria dos planos de aula (P2; P3; P4; P5; P6; P9; P11; P12; P13; P14, P16; P17; P18: P19; P21; $\mathrm{P} 22$; P23; P26), quer relativamente a atividades que implicavam a leitura de pequenos textos narrativos, quer no âmbito de obras integrais.

O cruzamento dos planos de aula com os registos das observações em contexto de supervisão (RO4; RO6; RO7) possibilitou-nos inferir que os estudantes manifestavam grande entusiasmo relativamente à apresentação dos textos no PowerPoint, entusiasmo não replicado nos alunos/nas alunas da respetiva turma. A preferência pelo PowerPoint poderá estar relacionada com as práticas educativas em que os estudantes participam no âmbito da sua formação, já que é amplamente utilizado em muitas aulas, sendo ainda comummente facultado enquanto material de apoio ao estudo. $\mathrm{O}$ quadro interativo foi igualmente privilegiado nas planificações dos estudantes (P1; P7; P8; P10; P15; P20; P24; P25), sobretudo no âmbito da resolução de alguns dos exercícios relativos à etapa da pós-leitura (nomeadamente questões relacionadas com a compreensão literal), relativamente aos textos narrativos. Alguns estudos têm apontado para as vantagens da utilização do quadro interativo na melhoria do processo de ensino/aprendizagem da leitura e da escrita (por exemplo, Dias, Gil \& Gonçalves, 2015), embora se reconheça a necessidade de incrementar a formação dos professores no que se refere à sua utilização em contexto educativo, em diferentes níveis de ensino (Ferreira, 2011; Sampaio \& Coutinho, 2013).

No que se refere aos planos de aula do $3 .^{\circ}$ ano de escolaridade (P27 a P52), foi possível inferir que os estudantes privilegiaram menos o suporte digital (P27; P33; P42; P51), recorrendo, com maior frequência, a livros (P27; P31; P32; P37; P39; P40; P45; P50) e a textos do manual escolar (P29; P30; P35; P41; P43; P44). As fichas de trabalho, elaboradas pelos estudantes para complementar o trabalho realizado com recurso ao manual escolar, foram também recorrentemente usadas. Importa salientar que o recurso a livros ocorreu, sobretudo, no âmbito da concretização do objetivo amplo «Explorar histórias» (P27; P31; P37; P39; P40), no que se refere ao texto narrativo.

No entanto, entendemos que o acolhimento dado ao livro não foi o expectável, dado que os estudantes: i) não estabeleceram objetivos que possibilitassem favorecer a motivação para a leitura; ii) não valorizaram, na maioria das planificações, o domínio da Educação Literária (como frisamos acima). Os registos das observações realizadas (RO5; RO6; RO7; RO8) possibilitaram corroborar tal desvalorização; quando os alunos/as alunas colocavam questões, em contexto de sala de aula, que revelavam o seu interesse, por exemplo, por elementos paratextuais, as suas observações eram depreciadas pelos/pelas futuros(as) professores(as).

Globalmente, no âmbito dos dois níveis de ensino considerados, houve, muitas vezes, falta de articulação entre os objetivos traçados e os recursos utilizados, possibilitando inferir que tal influencia o modo como os descritores de desempenho são operacionalizados nos domínios da Leitura e Escrita e da Educação Literária.

Os aspetos mencionados devem merecer particular atenção no que respeita à formação dos estudantes, entendendo-se que esta deverá ser consolidada através de fundamentação teórica rigorosa e adequada no âmbito da didática da leitura, da escrita e da literatura, aliada a uma ampla reflexão fundada em exemplos das práticas educativas.

\section{Considerações finais}

O estudo realizado possibilitou-nos inferir que as representações da leitura dos estudantes estavam muito entrelaçadas na «aquisição de conhecimentos», em detrimento do prazer e da fruição, aspetos particularmente patentes nas suas planificações, 
independentemente do nível de ensino. Tal influenciaria, pois, o modo como encaravam a Educação Literária, silenciando, muitas vezes, nos seus planos de aula, os objetivos e os descritores de desempenho que poderiam contribuir, de forma mais explícita, para motivar os alunos/as alunas para a leitura (podendo, assim, repercutir-se no seu futuro público).

A ausência do livro, no âmbito das planificações do 2. ${ }^{\circ}$ ano de escolaridade, e o uso reiterado do suporte digital não ancorado numa fundamentação que o legitime, daí retirando proveito, são aspetos que merecem atenção no futuro, pelas suas consequências no âmbito da promoção de práticas de leitura por prazer.

Importa frisar que a presença do livro, no que se refere às planificações do $3 .^{\circ}$ ano, também não se instituiu, por si só, enquanto garantia da sua valorização enquanto porta de entrada do(s) deslumbramento(s) (de) que se entretece (m) a(s) leitura(s) que fazemos. Destacou-se a depreciação dos elementos paratextuais, revelando-nos que nas representações da leitura e da educação literária destes estudantes estão ausentes aspetos que se prendem com a fruição estética do livro (e, por consequência, da leitura), influenciando os modos como os leitores veem e se reveem (n)o mesmo.

No que se refere à operacionalização dos descritores de desempenho nos domínios da Leitura e Escrita e da Educação Literária foi possível inferir que os estudantes privilegiavam, sobretudo, atividades em que predominava a pós-leitura, aspeto corroborado pelo modo como utilizavam os recursos que favoreceram nas suas planificações.

Entendemos que são necessários mais estudos que possibilitem lançar luz sobre a importância da educação literária e das representações da leitura no âmbito dos itinerários da formação de professores. Embora tal relevo esteja plasmado nos documentos curriculares em vigor, é necessário refletir, de forma atenta, sobre o modo como os estudantes as encaram, para que o redesenho da sua formação lhes possibilite valoriza-las devidamente.

\section{Referências}

Arruda, M. C. M. F. \& Guimarães, K. N. (2016). Formar professores para formar leitores: uma abordagem sobre o ensino da literatura. Anais do III CONEDU, Congresso Nacional de Educação (pp. 1-12). Campina Grande: Editora Realize. Disponível em http://www.editorarealize.com.br/revistas/conedu/trab alhos/TRABALHO EV056 MD1 SA4 ID5264 150 82016135320.pdf

Bardin, L. (2004). Análise de conteúdo, 3. a edição. Lisboa: Edições 70.

Buescu, H., Morais, J., Rocha, M. R. \& Magalhães, V. M. (2015). Programa e metas curriculares de Português do ensino básico. Lisboa: Direção-Geral da Educação.

Coutinho, C. P. (2011). Metodologia de investigação em ciências sociais e humanas: teoria e prática. Coimbra: Almedina.

Coutinho, C. P. (2015). Avaliação da qualidade da investigação qualitativa: algumas considerações teóricas e recomendações práticas. In F. Neri de Souza,
D. Neri de Souza e A. P. Costa (Orgs.) Investigação qualitativa: inovação, dilemas e desafios (pp. 103123). Oliveira de Azeméis: Ludomedia.

Dias, V., Gil, H. \& Gonçalves, T. (2015). O quadro interativo multimédia (QIM) num contexto de prática de ensino supervisionada em 1. ${ }^{\circ}$ CEB. Atas do XVII Simpósio Internacional de Informática Educativa (pp. 7-12). Disponível

em http://siie15.ese.ips.pt/ATASdoSIIE15.pdf

Fajardo, D. M. (2014). El potencial didáctico del libroálbum para la educación literaria-intercultural. Educar em Revista, 52, 45-68.

Ferreira, A. P. (2011). Utilização dos quadros interativos multimédia em contexto educativo; estudo de caso numa escola do ensino básico. (Dissertação de mestrado, não publicada). Bragança: Instituto Politécnico de Bragança.

Granado, C. (2014). Teachers as readers: a study of the reading habits of future teachers/ El docente como lector: estudio de los hábitos lectores de futuros maestros. Cultura y Educación/Culture and Education, 26 (1), 44-70. doi: 10.1080/11356405.2014.908666

Melão, D. (2016a). Representações sobre a leitura e sua influência em práticas educativas. Um estudo no 1 . $^{\circ}$ ciclo de Bolonha. (Tese de doutoramento; não publicada). Aveiro: Universidade de Aveiro.

Melão, D. (2016b). A formação do leitor no ensino superior: trajetórias de motivação para a leitura. Desenredo, 12, 2, 453-472. Disponível em http://seer.upf.br/index.php/rd/article/viewFile/6373/4 051

Olivares, E. M. \& Arbona, A. D. (2016). Virtualidades de la formación literaria en educación infantil. Elogio a la diversidad. Revista Iberoamericana de Educación, 72, 169-182.

Presidência do Conselho de Ministros (2017). Resolução do conselho de ministros, n. ${ }^{\circ}$ 48-D/2017, Diário da República, 1. ${ }^{a}$ série, 65, 31 de março. Disponível em http://data.dre.pt/eli/resolconsmin/48d/2017/03/31/p/d $\mathrm{re} / \mathrm{pt} / \mathrm{html}$

Saldanha, D. M. L. L. \& Amarilha, M. (2016). Literatura e formação do pedagogo: caminhos que (ainda) não se cruzam. Desenredo, 12, 2, 376-396. Disponível em http://seer.upf.br/index.php/rd/article/view/6389/4055

Sampaio, P. A. S. R. \& Coutinho, C. P. (2013). Quadros interativos na educação: uma avaliação a partir das pesquisas na área. Educação \& Pesquisa, 39, 3, 741$756 . \quad$ Disponível http://www.scielo.br/pdf/ep/v39n3/12.pdf

Sánchez, C. (2015). Orígenes y evolución de la investigación cualitativa en educación. In F. Neri de Souza, D. Neri de Souza e A. P. Costa (Orgs.) Investigação qualitativa: inovação, dilemas e desafios (pp. 41-74). Oliveira de Azeméis: Ludomedia.

Sánchez, M. I. M. (2016). Estrategias de formación lectora en la universidad. La literatura como ámbito transversal para un aprendizaje integrado de la cultura. Álabe, 13. doi: 10.15645/Alabe2016.13.2

Sebastián, R. G. (2016). Manual de literatura infantil y educación literária. Santander: Editorial de la Universidad de Cantabria. 
Souza, R. M. \& Carrera, R. M. H. (2017). Representações de percursos formativos de leitores universitários. In B. Merrill, J. González-Monteagudo, A. Nizinska, A. Galimberti e M. A. Ballesteros-Moscosio (Eds.) Adult learning, educational careers and social change (pp. 41-58). Seville: University of Seville.

\section{Agradecimentos}

Financiamento: Projeto Representações e Experiências da Leitura (Proj./CI\&DETS/2016/0013). 